\title{
Effects of polycyclic aromatic hydrocarbons and abiotic stressors on Fundulus grandis cardiac transcriptomics
}

\author{
Elizabeth Allmon ${ }^{a}$, Jennifer Serafin ${ }^{a}$, Shuai Chen ${ }^{a}$, Maria L. Rodgers ${ }^{b}$, Robert Griffitt ${ }^{b}$, Thijs Bosker ${ }^{c}$, \\ Sylvain de Guise ${ }^{\mathrm{d}}$, Maria S. Sepúlveda ${ }^{\mathrm{a}, *}$ \\ a Department of Forestry and Natural Resources, Purdue University, West Lafayette, IN, USA \\ b Division of Coastal Sciences, School of Ocean Science and Engineering, University of Southern Mississippi, Ocean Springs, MS 39564, USA \\ ${ }^{c}$ Leiden University College and Institute of Environmental Sciences, Leiden University, Anna van Buerenplein 301, 2595 DG The Hague, the Netherlands \\ ${ }^{\mathrm{d}}$ Department of Pathobiology and Veterinary Science, University of Connecticut, Point61 North Eagleville Road, Storrs, CT 06269, USA
}

\section{H I G H L I G H T S}

- Salinity and temperature alone are not important drivers of gene expression.

- Genes involved in xenobiotic metabolism, cardiac development \& function upregulated

- Increased cardiomyocyte proliferation and hypertrophy \& inhibited contractility

- Systemic vasculature heavily impacted under multiple stressors

- Complex interactions under multiple stressors do not appear to be additive.

\section{A R T I C L E I N F O}

\section{Article history:}

Received 1 June 2020

Received in revised form 31 August 2020

Accepted 31 August 2020

Available online 6 September 2020

Editor: Yolanda Picó

\section{Keywords:}

Fish

Early life stage

Cardiac

Combined stressors

Oil

Hypoxia

\section{G R A P H I C A L A B S T R A C T}
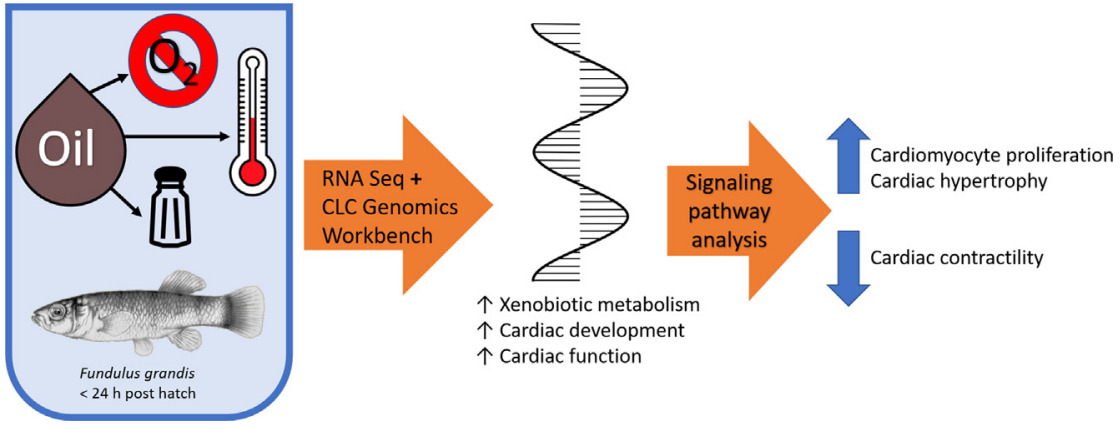

\begin{abstract}
A B S T R A C T
Following the 2010 Deepwater Horizon oil spill, extensive research has been conducted on the toxicity of oil and polycyclic aromatic hydrocarbons (PAHs) in the aquatic environment. Many studies have identified the toxicological effects of PAHs in estuarine and marine fishes, however, only recently has work begun to identify the combinatorial effect of PAHs and abiotic environmental factors such as hypoxia, salinity, and temperature. This study aims to characterize the combined effects of abiotic stressors and PAH exposure on the cardiac transcriptomes of developing Fundulus grandis larvae. In this study, F. grandis larvae were exposed to varying environmental conditions (dissolved oxygen (DO) $2,6 \mathrm{ppm}$; temperature $20,30^{\circ} \mathrm{C}$; and salinity $3,30 \mathrm{ppt}$ ) as well as to a single concentration of high energy water accommodated fraction (HEWAF) ( $\sum \mathrm{PAHs} 15 \mathrm{ppb}$ ). Whole larvae were sampled for RNA and transcriptional changes were quantified using RNA-Seq followed by qPCR for a set of target genes. Analysis revealed that exposure to oil and abiotic stressors impacts signaling pathways associated with cardiovascular function. Specifically, combined exposures appear to reduce development of the systemic vasculature as well as strongly impact the cardiac musculature through cardiomyocyte proliferation resulting in inhibited cardiac function and modulated blood pressure maintenance. Results of this study provide a holistic view of impacts of PAHs and common environmental stressors on the cardiac system in early life stage estuarine species. To our knowledge, this study is one of the first to simultaneously manipulate oil exposure with abiotic factors (DO, salinity, temperature) and the first to analyze cardiac transcriptional responses under these co-exposures.

(c) 2020 Elsevier B.V. All rights reserved.
\end{abstract}

\footnotetext{
* Corresponding author.

E-mail address: mssepulv@purdue.edu (M.S. Sepúlveda).
} 


\section{Introduction}

Coastal estuaries are dynamic environments that play an important role in the life cycle of many marine species. These inshore environments are subject to influences from adjacent inland watersheds as well as tidal influences from pelagic waters. This interplay creates complex biogeochemical profiles wherein fluctuating abiotic factors such as dissolved oxygen (DO), salinity, and water temperatures interact and influence organisms living within estuaries (Orlando et al., 1993; Schroeder and Wiseman, 1986). The Northern Gulf of Mexico annually undergoes seasonal intensification of the dead zone - a regional hypoxia event that forms at the mouth of the Mississippi River - in the late spring and summer months. During this time, Do levels within the water column drop to less than 2 ppm presenting oxic challenges to organisms residing in the dead zone (Rabalais et al., 2002). In addition to oxic challenges from the dead zone, estuaries in the Northern Gulf of Mexico undergo regular salinity fluctuations driven by changes in freshwater inputs from river discharge, precipitation, and tidally driven marine inputs. These fluctuations create brackish environments within estuaries with salinities that can range from fully fresh water $(0 \mathrm{ppt})$ to hypersaline environments (>35 ppt) (Orlando et al., 1993). Next, estuarine habitats are often very shallow and are therefore susceptible to changes in thermal regimes driven by ambient air temperatures, warm freshwater inputs from watersheds, and cooler marine waters driven in by tides (Schroeder and Wiseman, 1986). These dynamic interactions require the organisms that reside in these estuaries be capable of physiologically compensating for the changing environments (Bennett and Beitinger, 1997; Borowiec et al., 2015; Haney and Nordlie, 1997).

In addition to adapting to fluctuating abiotic factors, estuarine species are often faced with anthropogenic stressors. An important example is the Deepwater Horizon oil spill that occurred in the Northern Gulf of Mexico from April to September 2010 and released an estimated 4.9 million barrels of crude oil into the environment (Beyer et al., 2016; Camilli et al., 2012; McNutt et al., 2012; Norse and Amos, 2010). The plume from the wellhead reached the surface and created a slick that reached shorelines from Louisiana to Florida and was estimated to cover >26,000 mile (Beyer et al., 2016; Norse and Amos, 2010; Sammarco et al., 2013). The location and timing of the spill coincided with the annual development of the dead zone as well as the spawning periods for many pelagic and estuarine fish species (Esbaugh et al., 2016; Muhling et al., 2012; Rooker et al., 2013). Following the spill there has been a breadth of research on the effects of oil (see Murphy et al., 2016 for a literature review), particularly its primary constituents - polycyclic aromatic hydrocarbons (PAHs) - on the early life stages of fishes. Importantly, previous work with PAHs has shown that PAH toxicity in fish is variable, and depends on the life stage at the time of the exposure. PAHs can have adverse impacts on specific organ and systems (such as the cardiovascular system or the immune system), developmental stages, or act as potential mutagens or carcinogens (Carls et al., 2008; Carvalho et al., 2008; Collier et al., 2013; Edmunds et al., 2015; Esbaugh et al., 2016; Incardona et al., 2011, 2014; Jayasundara et al., 2015; Mager et al., 2014; Magnuson et al., 2018; Pan et al., 2018; Xu et al., 2016, 2017a).

While many studies have identified the toxicological effects of oil in estuarine and marine fishes (for a review, see Murphy et al., 2016), only recently has work begun to identify the combined effects of oil and abiotic environmental factors such as hypoxia, salinity, and temperature (Hedgpeth and Griffitt, 2016; Jasperse et al., 2019; Mauduit et al., 2018; Milinkovitch et al., 2020; Serafin et al., 2019; Simning et al., 2019). Specifically, a number of studies have found impacts of abiotic stressors on the developing cardiac system in fish. Cardiac impairments such as changes in heart rate, blood pressure, vasodilation, and cardiac remodeling are common when embryos are exposed to increased temperatures, elevated salinities, and/or low DO levels (Claireaux et al., 1995; Farrell, 2007; Keen et al., 2017; Klaiman et al., 2011; Lin et al., 1994; Randall and Smith, 1967). Similarly, exposure to PAHs under otherwise optimal environmental conditions have repeatedly shown cardiac effects including heart malformations, reductions in cardiac output, and increases in pericardial edema in both estuarine and pelagic fishes(Carls et al., 2008; Incardona et al., 2009, 2011, 2014; Jayasundara et al., 2015; Khursigara et al., 2017).

Currently, the combined effects of abiotic factors and PAH exposure on the developing cardiac system are largely unknown. This study aims to characterize these effects in developing Gulf killifish (Fundulus grandis). F. grandis is an estuarine species native to the Gulf of Mexico and alongside a closely related species (Fundulus heteroclitus) has been used as a model for toxicity testing in a number of PAH studies (Oleksiak et al., 2011; Powell et al., 2004; Reid et al., 2016; Whitehead et al., 2011). F. grandis inhabit nearshore environments that undergo daily and seasonal fluctuations in temperature, salinity, and DO. They are also widely dispersed in estuaries directly impacted by the Deepwater Horizon oil spill and their spawning seasons directly coincided with the timing of the spill (Greely and MacGregor, 1983), making them ideal candidates for the study of the combined effects of oil and abiotic factors on transcriptional responses in the developing cardiac system. We hypothesize that exposure to PAHs or environmentally relevant abiotic factors (hypoxia, salinity, temperature) will result in changes to cardiac related transcriptional responses. Additionally, we expect that the combination of PAHs with an abiotic factor will result in altered transcriptional responses relative to independent exposure to PAHs or abiotic factors alone.

\section{Materials and methods}

\subsection{Broodstock collection and spawning}

Wild caught adult $F$. grandis broodstock were collected from Mississippi estuaries in Gautier, Ocean Springs, Deer Island, and Bay St. Louis in March 2015. Fish underwent a 14-day quarantine period upon arrival to Purdue Aquaculture Research Lab at Purdue University, West Lafayette, Indiana, USA. Fish were maintained in $130 \mathrm{~L}$ aquaria at $25 \pm$ $1{ }^{\circ} \mathrm{C}, 6 \mathrm{mg} / \mathrm{L} \mathrm{DO}, 10 \mathrm{ppt}$ salinity (reconstituted saltwater prepared with Fritz SuperSalt Concentrate, Fritz Industries, Mesquite, TX, USA), and $16 \mathrm{~L}: 8 \mathrm{D}$ photoperiod. Fish were fed to satiation twice daily with frozen chironomids (morning) and frozen brine shrimp (JEHM Co., Lambertville, NJ, USA) (evening). A single mating pair of $F$. grandis was bred 2-3 times per week and embryos were collected on Pentair polyester filter mats (Minneapolis, MN, USA) using techniques described by Green, 2013. Embryos were then transferred to floating mesh cylinders $(15 \mathrm{~cm} \times 5 \mathrm{~cm})$ in the adult tanks from which they were collected and were monitored daily until hatch.

\subsection{Exposure design}

F. grandis larvae ( $<24 \mathrm{~h}$ post hatch) were randomly chosen and placed in individual $125 \mathrm{~mL}$ glass jars sealed with Teflon lined caps. A fully factorial design was used to combine PAH exposure $(0,15 \mu \mathrm{g} / \mathrm{L})$, DO $\left(2,6\right.$ ppm), salinity $(3,30 \mathrm{ppt})$, and temperature $\left(20,30^{\circ} \mathrm{C}\right) ; n=$ 9 larvae per treatment. Exposure chambers were maintained within temperature controlled environmental chambers with a $16 \mathrm{~L}: 8 \mathrm{D}$ photoperiod. Hypoxic conditions ( $\mathrm{DO} \leq 2 \mathrm{ppm}$ ) were established through aeration with nitrogen gas. Salinity was maintained using reconstituted saltwater at the appropriate salinity as described above. Exposures lasted $48 \mathrm{~h}$ with water quality monitored daily. Fish were not fed during the course of the exposure as they were still reliant on yolk sac. There were 9 replicates (one larvae per replicate) per treatment.

\subsection{High energy water accommodated fraction (HEWAF) preparation}

Macondo crude oil ( $1 \mathrm{~g} / \mathrm{L})$ was blended with seawater using a stainless steel blender (Waring, Stamford, CT, USA) at low speed for $30 \mathrm{~s}$, utilizing previously established methods (Forth et al., 2017b, 2017a). 
HEWAF was allowed to settle for $1 \mathrm{~h}$ in a glass separatory funnel before $450 \mathrm{~mL}$ was drained and used immediately for exposures.

\subsection{PAH analysis}

Gas chromatography coupled with tandem mass spectrometry (GC) MS/MS) was used to quantify concentrations of 29 parent PAHs, alkyl PAHs, and alkyl PAH homologs from stock solutions at the University of Connecticut Center for Environmental Sciences and Engineering (Storrs, CT, USA). PAH concentrations from HEWAF dilutions and test solutions over time were calculated using fluorescence methodology by measuring fluorescence between 270 and $380 \mathrm{~nm}$ (Greer et al., 2012). See Serafin et al. (2019), Table S2 for total PAH concentrations and the 29 analytes quantified (tPAH29).

\subsection{Water chemistry}

Temperature, DO, salinity, and PAH content were measured at the onset of exposures and throughout the $48 \mathrm{~h}$ exposure. Temperature and DO were measured using a YSI PRO 1020 multi-parameter meter. Salinity was measured using a Pentair Vital Sine SR6 handheld refractometer. PAH concentrations were indirectly quantified through fluorometry (Greer et al., 2012) using a Turner Designs AU-10 fluorometer (Turner Designs, San Jose, CA, USA). For full water chemistry methodology see Serafin et al. (2019).

\section{6. $R N A$ isolation/RNA Seq}

Following $48 \mathrm{~h}$ exposures, individuals were collected for RNA analysis. To ensure sufficient RNA, three larvae were pooled to constitute one replicate, resulting in three replicates per treatment. RNA isolation was completed using RNeasy Mini Kits (Qiagen, Valencia, CA, USA) according to manufacturer's protocols. RNA quantification was measured using a NanoDrop 2000 spectrophotometer and associated software (Thermo Fisher, Waltham, MA, USA). RNA sequencing (RNAseq) was performed at the Purdue University Genomics Core Facility (West Lafayette, IN, USA) with an Illumina HiSeq 2500 (Illumina, San Diego, CA, USA) to sequence a minimum of 15 million $2 \times 100$ bp sequencing reads; average sequencing depth was 23 million reads/sample.

\subsection{Bioinformatic analysis}

All gene expression data have been submitted and archived through the Gulf of Mexico Research Initiative Information \& Data Cooperative (GRIIDC). Sequenced reads were quality checked using the FastQC toolkit (Andrews, 2010), adapter sequences and low-quality reads were trimmed using Trimmomatic (Bolger et al., 2014), and a postcleaning quality check was run again using FastQC. Filtered sequences were loaded into CLC Genomics Workbench (Qiagen, Hilden, Germany) where paired-end reads were merged and mapped to the F. heteroclitus reference genome (NCBI genome: 743) with > 94\% mapping success. Gene expression values were calculated as transcripts per million and differential expression was calculated in the CLC Genomics Workbench. Differentially expressed genes (DEGs) were defined as those with an FDR $p$-value $\leq 0.05$ when compared to expression under control conditions. Heat maps for DEGs using Euclidean distance hierarchical clustering and complete linkages were created in $\mathrm{R}$ using pheatmap package (Kolde, 2012). DEGs were converted to their human orthologs and analyzed using Ingenuity Pathway Analysis (IPA) (Qiagen, Hilden, Germany) software with a FDR $p$-value cut-off at 0.05 to predict downstream pathways and functions. IPA provides a widely curated database of human and mammalian gene-association findings that allow for deeper analysis of gene interactions and associated downstream pathways and functions than data currently available for teleost models alone (Jones et al., 2020; Xu et al., 2017a, 2017b). For DEG analysis and pathway analysis, treatment groups were compared to the control group ( $\sum \mathrm{PAH}=0 \mu \mathrm{g} / \mathrm{L}, \mathrm{DO}=6 \mathrm{ppm}$, salinity $=3 \mathrm{ppt}$, temperature $=20^{\circ} \mathrm{C}$ ). In order to maintain the cardiac related scope of this analysis, only canonical pathways, toxicological functions, and disease/biofunctions related to cardiac effects were included (Rodgers et al., 2018; Serafin et al., 2019).

\subsection{RT qPCR analysis}

Subsets of RNA isolate samples collected for RNA Seq analysis were also used for real-time qPCR validation ( 3 pools of 3 larvae each per treatment). Isolated RNA was converted to cDNA using a HighCapacity cDNA Reverse Transcription Kit (Thermo Fisher, Waltham, MA, USA), cDNA concentrations were verified on a NanoDrop 2000 spectrophotometer and associated software (Thermo Fisher, Waltham, MA, USA). RT qPCR was conducted on a Bio-Rad CFX Connect RealTime PCR System utilizing iQ SYBR Green Supermix (Bio-Rad, Hercules, CA) following the thermal cycling protocol provided by the manufacturer. Primers were supplied by Integrated DNA Technologies (Coralville, IA). Primer sequences were designed through Primer3Plus software (Untergasser et al., 2007) using NCBI nucleotide sequence data. Full primer sequences and NCBI accession numbers are listed in Table 1. Reaction efficiencies for each primer pair were determined through serially diluted standard curves with all reaction efficiencies between $90 \%$ and $103 \%\left(R^{2} \geq 0.99\right)$. Relative abundance of each gene in relation to the control gene $\beta$-actin was analyzed using the deltadelta CT method (Vandesompele et al., 2002). Note that $\beta$-actin is a common housekeeping gene with $\mathrm{CT}$ values that remained stable across all conditions tested. Statistical analysis of gene expression data for all treatments was done using one-way ANOVAs and Holm-Sidak pairwise multiple comparison versus control group post-hoc tests with fiducial level of significance of $p \leq 0.05$. All comparisons passed normality (Shapiro-Wilk) and equal variance (Brown-Forsythe) tests. All statistical variables are presented in Supplemental Table 1.

\section{Results}

\subsection{Water quality}

While this experiment consisted of a fully factorial design that included up to four environmental stressors, to conserve power within analyses, only treatments that included a single factor deviation from control (oil, hypoxia, salinity, or temperature) and treatments that included binary combinations of oil and a single abiotic factor (i.e. oil + hypoxia) were included in this analysis. Nominal exposure conditions ( $\sum \mathrm{PAH}, \mathrm{DO}$, salinity, and temperature) for all treatments included in analysis are listed in Table $2 \mathrm{~A}$ with associated measurements of water quality parameters in Table 2B. Temperatures and salinities were maintained at $\pm 1{ }^{\circ} \mathrm{C}$ and $\pm 1 \mathrm{ppt}$ nominal concentrations, respectively. Over the course of the $48 \mathrm{~h}$ exposure, DO decreased by an average of $2.2 \pm$ $0.6 \mathrm{ppm}$ under normoxic conditions and $1 \pm 0.8 \mathrm{ppm}$ under hypoxic conditions. Initial $\sum \mathrm{PAH}$ values for all exposures involving oil were $15.3 \pm 1.15 \mathrm{ppb}$ (Serafin et al., 2019). For a detailed description of water quality parameters and PAH decline over the $48 \mathrm{~h}$ exposure period see Serafin et al. (2019).

\subsection{Differential expression}

Differential expression analysis revealed a total of 494 DEGs within the cardiac-related pathways analyzed across all treatment groups (Supplemental Table 2). Fig. 1 shows the hierarchical clustering of all DEGs according to treatments. The most obvious pattern that emerged during clustering was the role of oil in the structuring of the transcriptional response of cardiac-related genes; oil (104 DEGs) and oil + hypoxia (160 DEGs) treatments clustered closely followed by the oil + salinity (225 DEGs) and oil + temperature (338 DEGs) treatments. The hypoxia only (137 DEGs) and salinity only (123 DEGs) 
Table 1

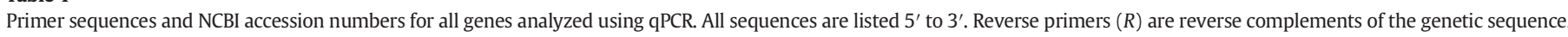

\begin{tabular}{|c|c|c|c|c|c|}
\hline \multirow{2}{*}{$\begin{array}{l}\text { Gene name } \\
\beta \text {-actin }\end{array}$} & \multicolumn{2}{|c|}{ Sequence $\left(5^{\prime}-3^{\prime}\right)$} & \multirow{2}{*}{$\begin{array}{l}\text { Efficiency } \\
90 \%\end{array}$} & \multirow{2}{*}{$\begin{array}{l}\text { NCBI accession \# } \\
\text { XM_012850364 }\end{array}$} & \multirow{2}{*}{$\begin{array}{l}\text { Product Length } \\
136 \mathrm{bp}\end{array}$} \\
\hline & $F$ & GCTCTGTGCAGAACAACCACACAT & & & \\
\hline & $R$ & TAACGCCTCCTTCATCGTTCCAGT & & & \\
\hline \multirow[t]{2}{*}{ ahrr } & $F$ & AGCTATGCAGTCAACAACGG & $98.8 \%$ & NM_001309962.1 & 385 bp \\
\hline & $R$ & СТСТСТСТСАTTGCATGTAAACG & & & \\
\hline \multirow[t]{2}{*}{ ugt1a1 } & $F$ & AGGATGGCATGTCTTACAAGG & $102 \%$ & XM_012854427.1 & 321 bp \\
\hline & $R$ & GCACATCTTTGGGTAAATCGC & & & \\
\hline \multirow[t]{2}{*}{ cyp1a } & $F$ & TGTTGCCAATGTGATCTGTG & $93 \%$ & NM_001310009 & 258 bp \\
\hline & $R$ & CGGATGTTGTCCTTGTCAAA & & & \\
\hline \multirow[t]{2}{*}{ fbxo32 } & $F$ & AAAACAACAACGTCTCTGTGG & $99.7 \%$ & XM_012864657.1 & 178 bp \\
\hline & $R$ & TGAACGTAAATCCACTTCTCC & & & \\
\hline \multirow[t]{2}{*}{ fgf7 } & $F$ & GTCACTCAGAACACATTGACG & $97.6 \%$ & XM_012877162.1 & 604 bp \\
\hline & $R$ & AGTCATCAATCGTGAGGAACC & & & \\
\hline \multirow[t]{2}{*}{$m b$} & $F$ & ATGATATGGTTCTCAAGCACTGG & $104 \%$ & XM_012850507.1 & 111 bp \\
\hline & $R$ & GGAACAGCTTTTGGGTATCTGG & & & \\
\hline
\end{tabular}

treatments clustered closely together and were more similar to the treatments containing oil than the temperature alone treatment. The temperature treatment had the fewest DEGs (44) of all exposure groups and did not cluster closely with any additional treatment groups.

\section{3. $q P C R$ validation of RNA Seq DEGs}

Overall, qPCR data for genes involved in xenobiotic metabolism and cardiac function are in agreement to those seen in the RNA Seq data (Fig. 2). Genes involved in xenobiotic metabolism (ahrr, ugt1a1, and cyp1a) universally showed upregulation relative to controls in all exposures containing oil either singly or in combination with an abiotic stressor (Fig. 2A-C). Expression of ahrr was significantly increased in the oil, oil + hypoxia, oil + salinity, and oil + temperature exposures, but its expression was not significantly altered when exposed to an abiotic factor alone (Fig. 2A). Expression of ugt1a1 was significantly downregulated in the elevated temperature RNA Seq data; corresponding qPCR data showed a similar, but non-significant trend (Fig. 2B). Exposure to oil, and to oil + hypoxia, high salinity and high temperature caused an upregulation of ugt1a1 expression. Although cyp $1 a$ which was not differentially upregulated from the RNA Seq data, upregulation from qPCR data followed a similar trend with the previous two genes,

Table 2

A) Nominal treatment exposure conditions (Oil concentrations, DO, salinity, and temperature). Conditions that deviate from control are bold. B) Initial $(0 \mathrm{~h})$ and final $(48 \mathrm{~h})$ water quality values for each test condition. Values represented as mean \pm S.D.

\begin{tabular}{|c|c|c|c|c|c|}
\hline \multicolumn{6}{|l|}{ A } \\
\hline Treatment & \multicolumn{2}{|c|}{$\begin{array}{l}\text { Oil } \\
\left.\text { (ppb } \sum \mathrm{PAH}\right)\end{array}$} & $\begin{array}{l}\text { DO } \\
(\mathrm{ppm})\end{array}$ & $\begin{array}{l}\text { Salinity } \\
\text { (ppt) }\end{array}$ & $\begin{array}{l}\text { Temperature } \\
\left({ }^{\circ} \mathrm{C}\right)\end{array}$ \\
\hline Control & 0 & & 6 & 3 & 20 \\
\hline Oil & 15 & & 6 & 3 & 20 \\
\hline Hypoxia & 0 & & $\leq 2$ & 3 & 20 \\
\hline Oil \& hypoxia & 15 & & $\leq 2$ & 3 & 20 \\
\hline Salinity & 0 & & 6 & 30 & 20 \\
\hline Oil \& salinity & 15 & & 6 & 30 & 20 \\
\hline Temperature & 0 & & 6 & 3 & 30 \\
\hline $\begin{array}{l}\text { Oil \& } \\
\quad \text { temperature }\end{array}$ & 15 & & 6 & 3 & 30 \\
\hline \multicolumn{6}{|l|}{ B } \\
\hline Condition & Nominal value & Ini & value $(0 \mathrm{~h})$ & & Final value (48 h) \\
\hline \multirow[t]{2}{*}{ Oil } & $0 \mathrm{ppb} \sum \mathrm{PAH}$ & $0 \mathrm{p}$ & $\sum \mathrm{PAH}$ & & $0 \mathrm{ppb} \sum \mathrm{PAH}$ \\
\hline & $15 \mathrm{ppb} \sum \mathrm{PAH}$ & 15 & $\pm 1.15 \mathrm{ppb} \Sigma$ & СРАН & $1 \pm 2.9 \mathrm{ppb} \sum \mathrm{PAH}$ \\
\hline \multirow[t]{2}{*}{ DO } & $6 \mathrm{ppm}$ & $6 \mathrm{r}$ & & & $2.2 \pm 0.6 \mathrm{ppm}$ \\
\hline & $\leq 2 \mathrm{ppm}$ & $2 \mathrm{p}$ & & & $1 \pm 0.8 \mathrm{ppm}$ \\
\hline \multirow[t]{2}{*}{ Salinity } & $3 \mathrm{ppt}$ & $3=$ & $.5 \mathrm{ppt}$ & & $3 \pm 0.5 \mathrm{ppt}$ \\
\hline & $30 \mathrm{ppt}$ & 30 & $0.5 \mathrm{ppt}$ & & $30 \pm 0.5 \mathrm{ppt}$ \\
\hline \multirow[t]{2}{*}{ Temperature } & $20{ }^{\circ} \mathrm{C}$ & 20 & $1{ }^{\circ} \mathrm{C}$ & & $20 \pm 1{ }^{\circ} \mathrm{C}$ \\
\hline & $30{ }^{\circ} \mathrm{C}$ & 30 & $1{ }^{\circ} \mathrm{C}$ & & $30 \pm 1{ }^{\circ} \mathrm{C}$ \\
\hline
\end{tabular}

with an upregulation in all treatments involving oil exposure and in any single abiotic stressor treatment + oil (Fig. 2C).

Expression trends in genes involved in cardiac formation and function were also similar between the qPCR and RNA Seq data. Expression

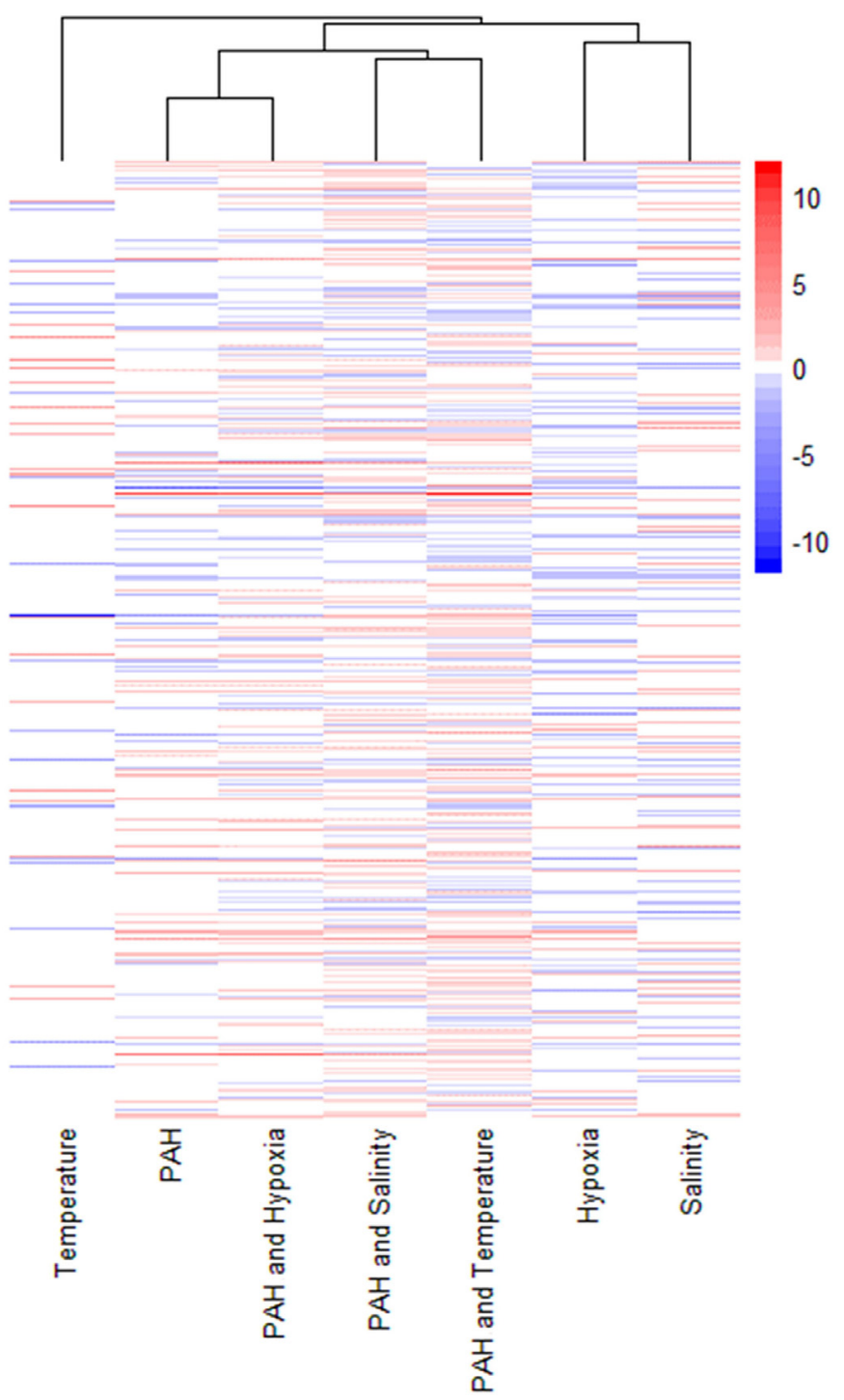

Fig. 1. Heatmap with hierarchical clustering of cardiac related differentially expressed genes across all treatments relative to control ( 0 ppb tPAH, $6 \mathrm{ppm} \mathrm{DO}, 3 \mathrm{ppt}, 30^{\circ} \mathrm{C}$ ). Warm shades (reds) indicate increased expression, cool shades (blues) indicate reduced expression. 


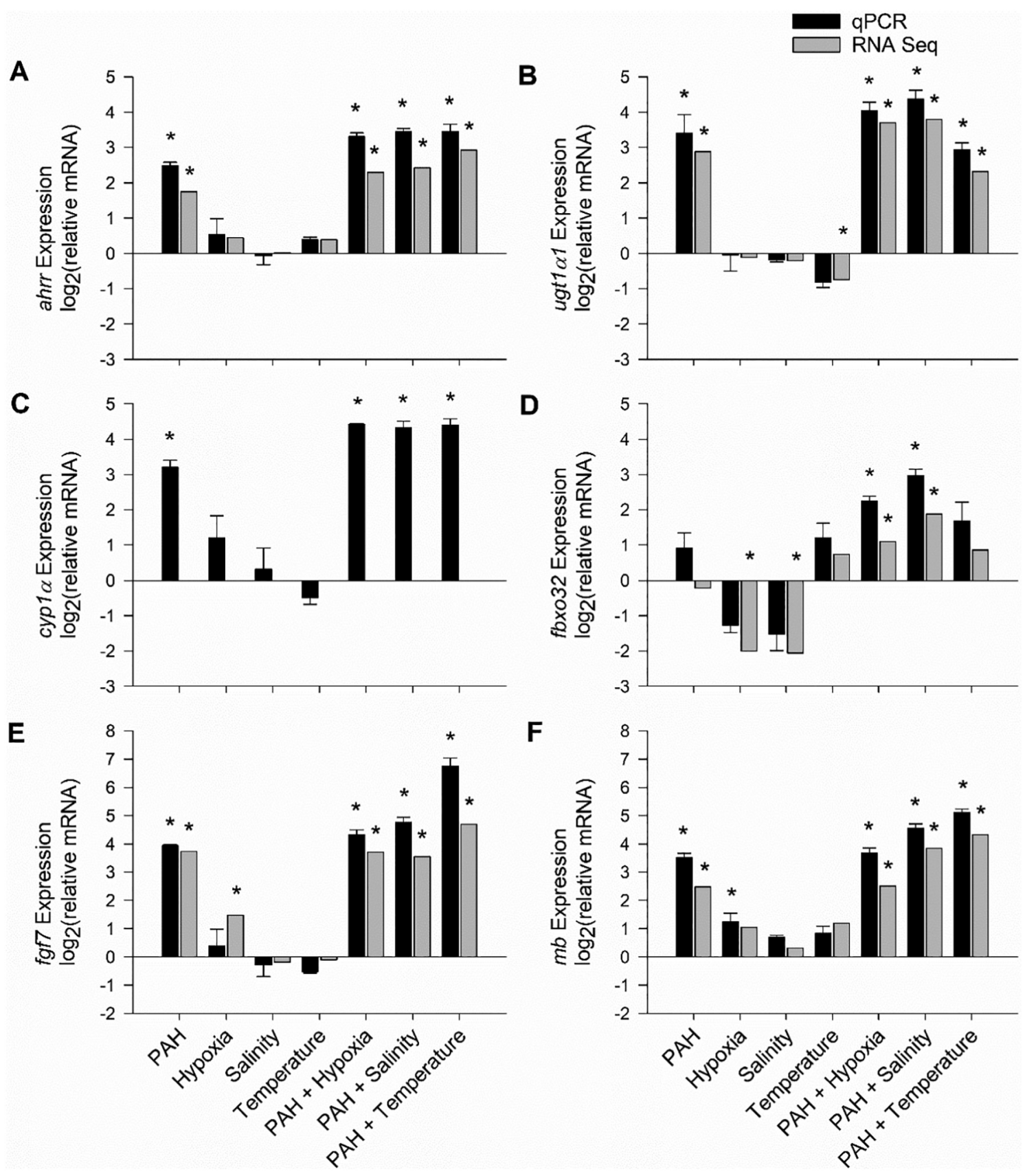

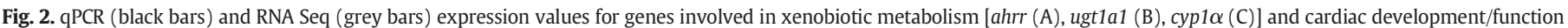

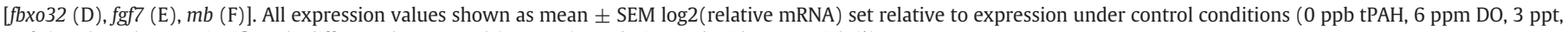
$\left.20^{\circ} \mathrm{C}\right)$. Values that are significantly different than control $(p \leq 0.05)$ are designated with an asterisk $\left({ }^{*}\right)$.

of fbxo32 was not significantly impacted under oil only, elevated temperature, or the combination of oil + temperature (Fig. 2D). In contrast, under hypoxic and elevated salinity conditions, RNA Seq measurements showed a significant decrease in fbxo32 transcripts; similarly, qPCR measurements showed reduced, but non-significant fbxo32 expression. fbxo32 expression was significantly upregulated in the combination treatments of oil + hypoxia and oil + salinity. Expression of $f g f 7$ was not significantly impacted under elevated temperature or elevated salinity (Fig. 2E). Exposure to hypoxia in the absence of oil significantly increased the number of $f g f 7$ transcripts measured through RNA Seq and although not significant, the qPCR expression of $f g f 7$ was also increased relative to control. All exposures involving oil exhibited significantly increased expression of $f g f 7$ with the combined exposure of oil + temperature having qPCR expression levels significantly higher than oil alone.
Similarly, all exposures including oil induced significant increases in expression of $m b$ with the oil + temperature exposure significantly higher than the oil alone exposure (Fig. 2F). Hypoxia alone also induced a significant increase in $m b$ in the qPCR data and a non-significant increase in the RNA Seq data. There were no differences from control in $\mathrm{mb}$ expression in the elevated salinity and temperature exposures.

\subsection{Canonical pathway analysis}

Analyses conducted through IPA included only those predicted pathways and functions that showed both a significant response $(p<0.05)$ and directional response (activation $z$-score $\neq 0$ ) in at least one treatment. Pathway analysis showed DEGs involved in 18 cardiac-related canonical pathways exhibiting a significant transcriptional response in at 
least one treatment (Fig. 3). Impacted pathways have roles in several cardiac functions including vasodilation, blood pressure maintenance, cell proliferation, hypertrophy, and contractility. Inhibition of calcium signaling was the only response that remained consistent among all treatments. Single exposures to abiotic factors tended to inhibit signaling pathways (as indicated by negative activation z-scores and shades of blue in Fig. 3). Exposure to elevated temperature alone induced almost no changes in canonical pathways except for a slight inhibition in calcium signaling. Combined exposures to oil and abiotic factors tended to activate pathways involved in cell proliferation and hypertrophy (positive activation z-scores and shades of orange in Fig. 3 ) as well as reduced angiogenesis.

\subsection{Toxicological function analysis}

Further analysis through IPA identified 26 toxicological functions across all treatments that were both significantly impacted and showed directionality (Fig. 4). Toxicological functions were identified using the human orthologs of DEGs and as such, interpretation of results must be done with caution. Additionally, variants of several functions appear multiple times within the resulting list of impacted toxicological functions (i.e. congenital heart disease and familial congenital heart disease). These 26 functions can be grouped together and reduced to represent 9 broad toxicological functions: Heart malformations, congenital heart defects, congestive heart failure/pericardial edema, cardiomyocyte proliferation, cardiomyocyte death, heart damage, hypertrophy, arrythmia, and heart dysfunction/failure.

In general, toxicological function analysis aligns well with canonical pathway analysis. Similar to the results from the canonical pathway analysis, general trends in increased cellular proliferation and hypertrophy and inhibited contractility were identified by the toxicological function analysis. Exposure to oil alone resulted in activation of congenital cardiac defects, cardiac hypertrophy, and increased cardiac dysfunction/failure. Exposure to hypoxia or elevated salinity resulted in similar responses of increased cardiac malformations and congenital cardiac defects. Like the DEG and canonical pathway results, elevated temperature alone resulted in few impacted toxicological functions. Broadly, trends in combined oil + hypoxia and oil + salinity responses followed those seen in their respective single abiotic factor responses. The combined effects of oil and elevated temperature, however, did not follow trends in either oil alone or temperature alone treatments; responses included activation of cardiomyocyte proliferation and hypertrophy, inhibition of cardiomyocyte death, and inhibition of cardiac malformations and congenital defects.

\subsection{Diseases/biofunction analysis}

IPA analysis into diseases and biofunctions revealed an overall trend in activation across exposures with most responses occurring in oil alone, hypoxia, and oil + hypoxia exposures (total of 26 functions impacted, Fig. 5). As with previously discussed IPA analyses, elevated temperature alone resulted in few impacted functions. Increased salinity and the combination of oil + salinity also showed little response at this level of analysis. Responses included effects on vasculature development, fatty plaque formations, and blood pressure disorders. Diseases involved in development of vasculature (vascular lesions, outgrowth of vasculature, and others) were activated in all exposures involving oil, which aligns with the inhibition of angiogenesis seen in the canonical pathway analysis (Fig. 5). Responses that suggest increases in fatty plaque formations (atherosclerosis, foam cells, and hypertriglyceridemia) were only present in oil, hypoxia, and oil + hypoxia exposures. Impacts on blood pressure disorders were seen in all exposures involving oil. These results are supported by those from the canonical pathway analysis in that the inhibition of blood pressure disorders seen in the combined oil + abiotic factors align with the activation of signaling pathways involved in blood pressure maintenance (Aldosterone, Apelin, and Renin-Angiotensin).

\section{Discussion}

This study aimed to characterize the combined effects of oil exposure and sub-optimal abiotic factors on the transcription of cardiac related genes in early life history $F$. grandis. While other studies have described the effects of oil on the cardiac system of fish (Carls et al., 2008; Incardona et al., 2009, 2011, 2014; Jayasundara et al., 2015; Khursigara et al., 2017), to our knowledge none have expanded their

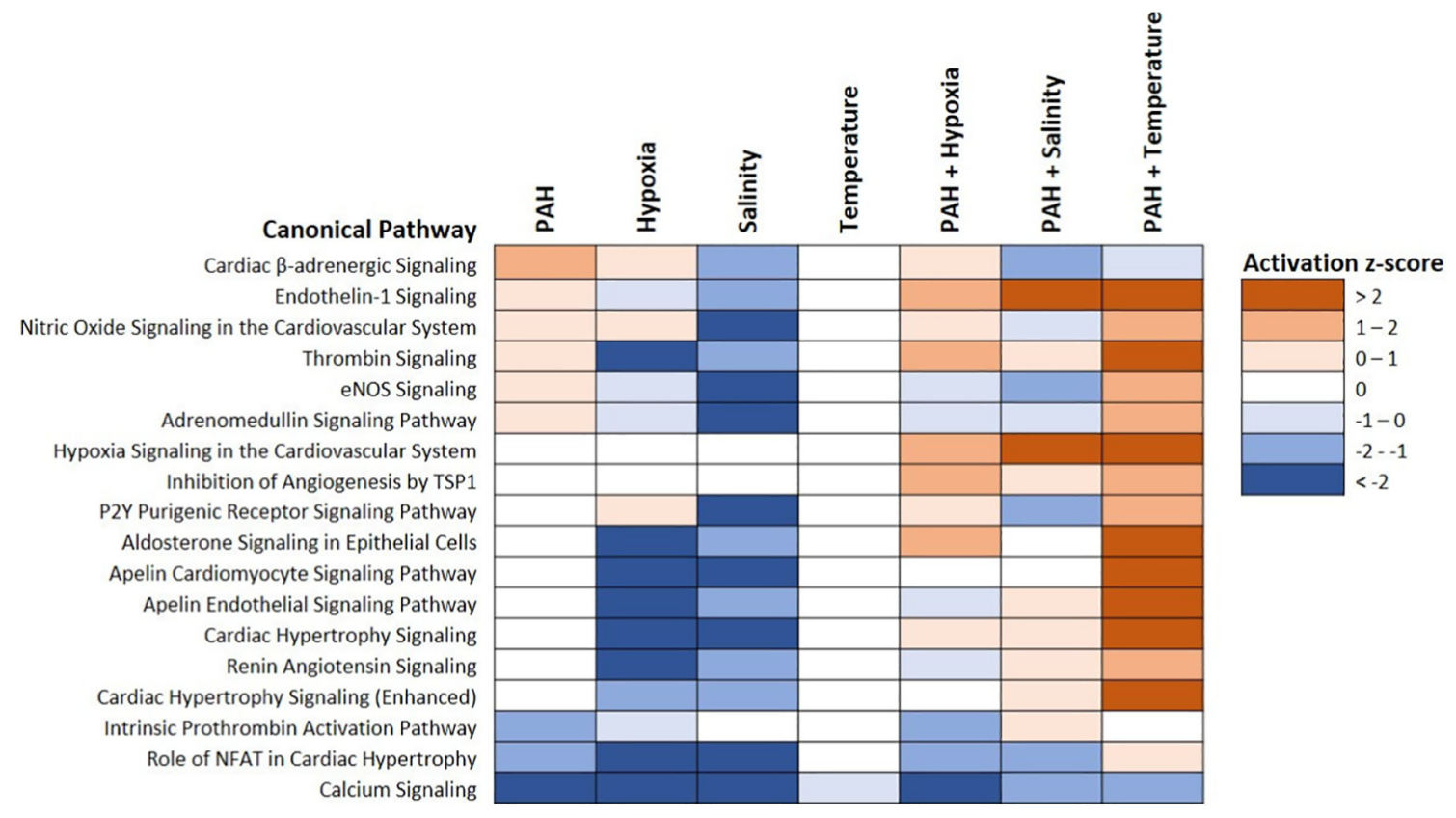

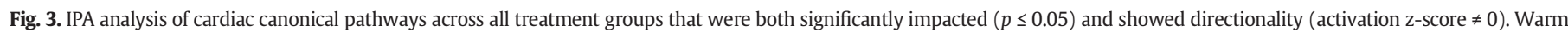
shades indicate pathway activation, cool shades indicate pathway inhibition. 


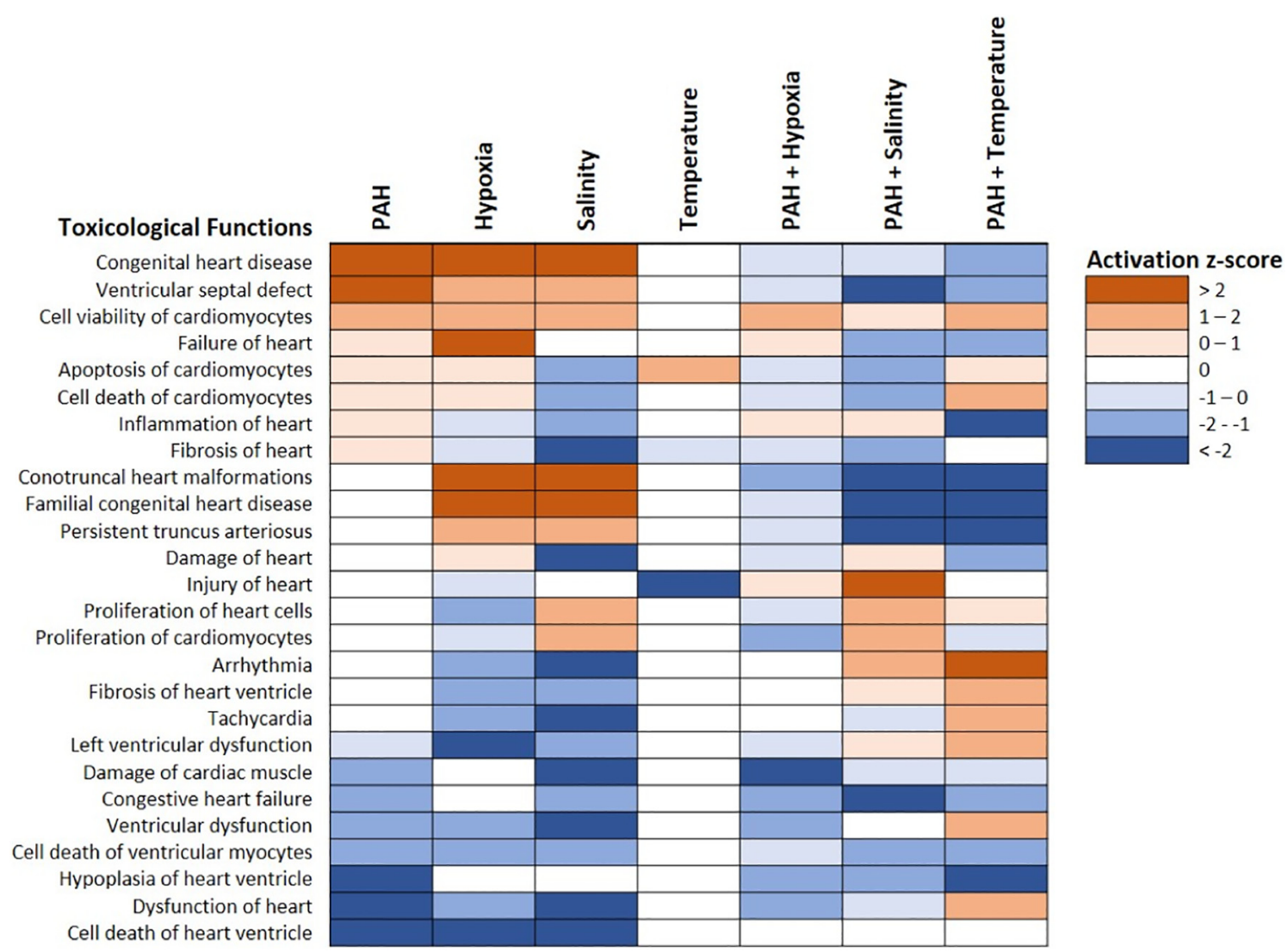

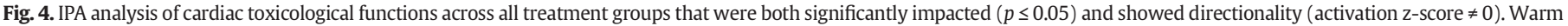
shades indicate function activation, cool shades indicate function inhibition.

assessment to include how dynamic environmental parameters (which are common in estuaries) influence these effects. Importantly, abiotic factors such as DO, salinity, and temperature have been shown to impact cardiac function independent of oil exposure through changes in heart rate, blood pressure, vasodilation, and cardiac remodeling - implying that environmental conditions play a key role in the development and function of the cardiac system in early life fish stages (Claireaux et al., 1995; Farrell, 2007; Keen et al., 2017; Klaiman et al., 2011; Randall and Smith, 1967). In addition, the cardiac transcriptome of early life stage fish has been shown to be responsive to the presence of oil and perturbations in environmental conditions (Xu et al., 2016, 2017a). Therefore, this study used the analysis of transcriptional changes in conjunction with predicted downstream pathway analysis to elucidate the impacts of both oil and sub-optimal abiotic factors on the cardiovascular system of larval $F$. grandis. Results presented here appear to support our hypothesis that exposure to PAHs and abiotic factors result in changes to cardiac related transcriptional responses. Further, there appears to be some evidence that combined exposure to oil and abiotic factors enhances these responses.

Analysis of the differential gene expression data suggests that the presence of oil is the strongest factor influencing transcriptional responses in the cardiac system under our exposure conditions. All exposures that included oil clustered closely together under the hierarchical clustering model, whereas exposures to individual abiotic factors did not cluster closely with any exposures involving oil. Within the oil cluster, the oil treatment alone and the oil + hypoxia treatment clustered most closely together, a trend that is reflected in downstream analyses through IPA. The combination of oil and an abiotic factor resulted in slightly more DEGs than exposure to any individual stressor, hinting that there may be a synergistic response when exposed to multiple stressors. This is most prominently seen in the oil + temperature exposure which resulted in more than triple the number of DEGs than the oil only exposure and a more than 7-fold increase in DEGs relative to the temperature alone exposure. While these results suggest a more than additive effect in DEG expression, a definitive statistical analysis could not be completed due to small sample sizes and additional exposures will need to be performed in order to verify the trends in the data. However, these DEG results suggest complex interactions between oil and abiotic factors are involved in mediating transcriptional cardiac responses.

A number of DEGs involved in xenobiotic metabolism and cardiac function were chosen for further analysis through qPCR. ahrr (arylhydrocarbon receptor repressor) is an important feedback modulator in the aryl-hydrocarbon receptor signaling cascade and has roles in regulating cell growth and differentiation (Clark et al., 2010). ugt1a1 (UDP glucuronosyltransferase 1a1) encodes an enzyme in the glucuronidation pathway that metabolizes lipophilic xenobiotics into water-soluble metabolites (Schlenk et al., 2008). cyp1 $\alpha$ (cytochrome p450 1a) is a member of the cytochrome $p 450$ family of enzymes which catalyzes reactions involved in xenobiotic metabolism; its expression is induced by the presence of PAHs (Schlenk et al., 2008). qPCR results for these genes involved in xenobiotic metabolism universally followed the same trends as those seen in the DEG analysis of RNA Seq data. As expected (Kim et al., 2018; Mimura et al., 1999; Shimada and Fujii-Kuriyama, 2004), each gene was significantly upregulated in every treatment involving oil exposure. cyp $1 \alpha$ expression profiles resulting from qPCR analysis followed expected trends as those seen in ahrr and ugt1a1 expression. Interestingly, cyp $1 \alpha$ did not exhibit significant differential expression in the RNA Seq dataset. Similarly, a lack of significant differential cyp $1 \alpha$ expression was observed in RNA Seq data for PAH exposed $F$. grandis analyzed using the Tuxedo protocol (Serafin, 2017). These parallel results suggest that the discrepancy 


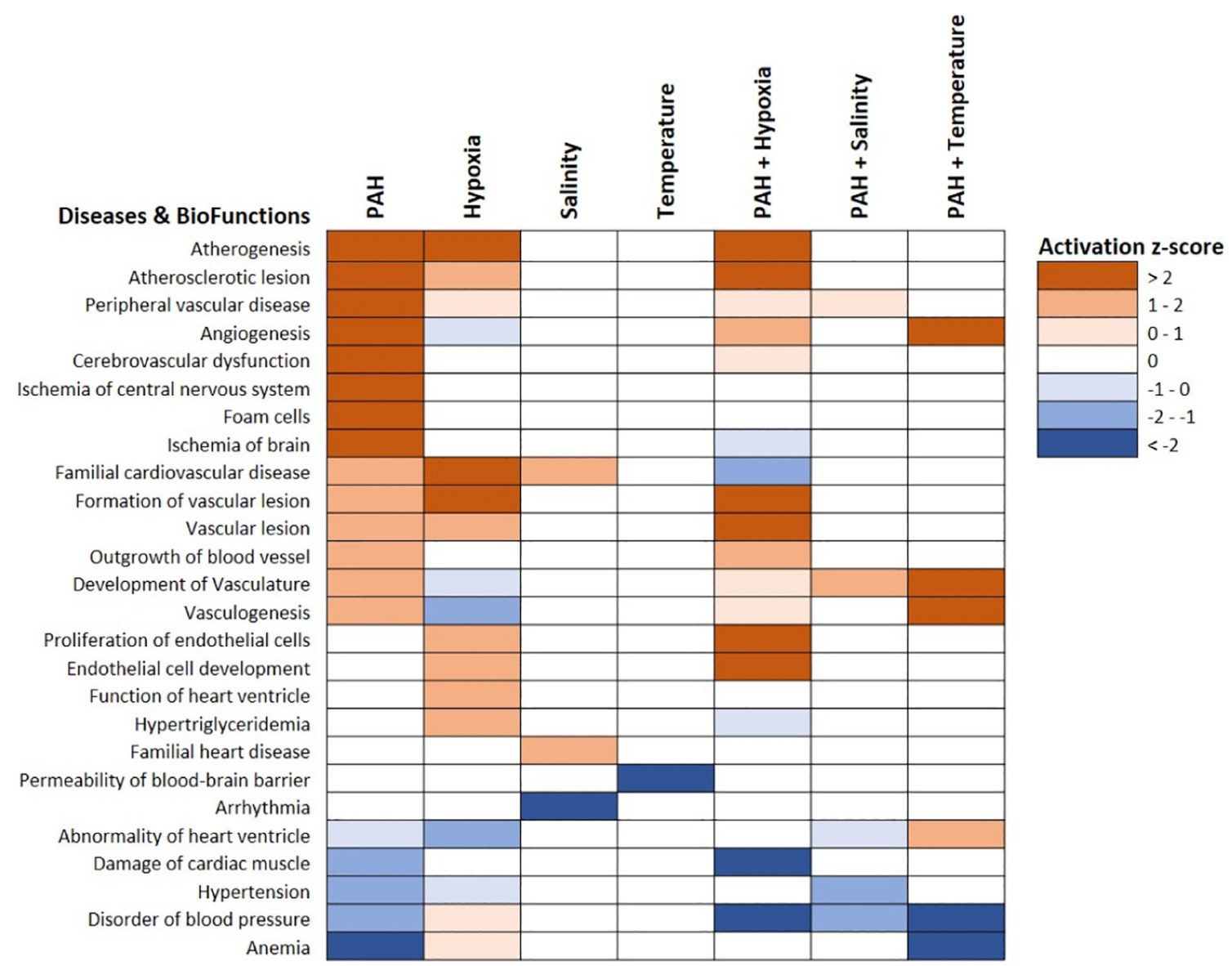

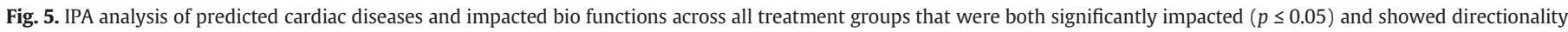
(activation $z$-score $\neq 0$ ). Warm shades indicate disease/biofunction activation, cool shades indicate disease/bio function inhibition.

between qPCR and RNA Seq analyses are not due to errors induced by the RNA Seq pipeline; rather, they highlight the different sensitivities between RNA Seq and qPCR methodologies. The cyp $1 \alpha$ qPCR product in this study is only $258 \mathrm{bp}$, while the RNA Seq methods attempt to map reads to the whole gene of $2708 \mathrm{bp}$. It is possible that the cyp1 $\alpha$ gene is not highly conserved between these two Fundulus species and the qPCR method caught the conserved region while much of the true $F$. grandis cyp $1 \alpha$ reads could not be mapped to the non-conserved F. heteroclitus cyp $1 \alpha$ region. This would result in the non-mapped reads being discarded and not appearing as DEGs in the downstream analysis.

Additional genes involved in cardiac development and function ( $f b x 032, f g f 7$, and $m b$ ) were assessed and the resulting qPCR trends, much like those involved in xenobiotic metabolism, matched closely with those seen in the RNA Seq data. fbxo32 (f-box protein 32) was only significantly upregulated in the combined oil + hypoxia and oil + salinity treatments. As fbxo32 is highly expressed during muscle atrophy (Cleveland and Evenhuis, 2010), its upregulation may suggest an increase in cellular death and dysfunction of the cardiac system under these combined conditions. Similarly, mammalian models have shown increased fbxo32 expression and associated muscle atrophy under hypoxic conditions (Bodine and Baehr, 2014; De Theije et al., 2015). fgf7 (fibroblast growth factor 7), which has roles in embryonic development, cell proliferation and differentiation, as well as cardiac morphogenesis (Zinkle and Mohammadi, 2019) was significantly upregulated in all treatments involving oil as well as the hypoxia only exposure. The expression pattern seen here is similar to $f g f 7$ expression patterns observed in polar cod exposed to PAHs, suggesting that fgf7 expression may also be sensitive to the presence of PAHs in the environment (Andersen et al., 2015). mb (myoglobin) expression followed similar patterns to $f g f 7$ and was upregulated in hypoxia and all exposures involving oil in both qPCR and RNA Seq datasets. As mb's primary function is intracellular oxygen storage (Bailey and Driedzic, 1986), this may be indicative of an increased oxygen demand under oil and/or hypoxia conditions. Indeed, in many fish species, exposure to hypoxia resulted in upregulation of myoglobin in muscle tissues (for a review, see Zhu et al., 2013). qPCR results presented here validate the trends seen in the RNA Seq differential gene expression analysis and further confirm that exposure to oil and abiotic environmental stressors are capable of eliciting responses in the expression of genes involved in detoxification and cardiac function/development in fish early life stages.

IPA identified 18 canonical pathways that were both significantly impacted and showed directionality in their responses. Impacted pathways affected are involved in regulating a number of cardiovascular functions including vasodilation, blood pressure maintenance, cell proliferation, cardiac hypertrophy, and contractility. Alone, exposure to abiotic factors largely resulted in the inhibition of many pathways including vasodilatory responses, blood pressure maintenance, contractility of the heart, and cardiomyocyte proliferation, which align with previous studies showing that hypoxia, salinity, and temperature can result in changes in heart rate, blood pressure, vasodilation, and cardiac remodeling (Claireaux et al., 1995; Farrell, 2007; Keen et al., 2017; Klaiman et al., 2011; Randall and Smith, 1967). When co-exposed with oil, responses appear to shift, and many pathways become activated. For instance, exposure to both oil and hypoxia results in increases in cell proliferation, cardiac hypertrophy, and contractility, and reduced angiogenesis; suggesting that cell growth may be increased in the heart but reduced throughout the rest of the cardiovascular system. Similar 
results were seen when fish were co-exposed to oil and salinity stress, i.e., increased signaling of cellular proliferation, hypertrophy, and cardiac tissue remodeling and reductions in contractility, angiogenesis, and vasodilation. These results again are suggestive of increased cardiomyocyte growth but reduced cellular proliferation throughout the rest of the cardiovascular system. This likely puts additional stress on the heart as increased cardiomyocyte proliferation and cardiac hypertrophy thickens the walls of the heart resulting in reduced elasticity and contractility. Much like results from the DEG analysis, exposure to elevated temperature alone elicited almost no response in the canonical pathway analysis, but when combined with oil exposure, elevated temperature resulted in the strongest canonical pathway responses. These pathways, especially those that were not impacted in either the oil alone or temperature alone exposures - such as the activation of Aldosterone and Apelin signaling pathways - suggests that exposure to multiple stressors can induce complex responses in developing fish. Responses in the combined oil and temperature exposure were similar to other binary exposures and included increased cardiomyocyte proliferation, cardiac hypertrophy, and contractility as well as reduced angiogenesis. Further suggesting that cardiac impairment occurs through morphological changes in the cardiac musculature that then drives alterations in the function of the cardiac system.

Further analysis through IPA into impacted toxicological functions yielded results similar to those seen in the canonical pathway analysis. It is important to note that IPA runs analysis on the human orthologs of the DEGs identified in the RNA Seq data and therefore, the functional analysis is based on human/mammalian functions. As such, a number of functions identified in this analysis are repetitious - for example "Congenital heart disease" and "Familial congenital heart disease" were both identified as functions impacted by the exposures (Fig. 4). Trends generally follow those seen in canonical pathway analysis for functions involving increases in cardiomyocyte proliferation, inhibited contractility, and increased hypertrophy across treatments, strengthening the conclusion that cardiac impairment is driven by thickening of the heart walls. Additionally, the functions most strongly impacted appear to switch from activation states to inhibition states when going from a single abiotic stressor to combined exposures with oil (i.e. "Congenital heart disease", Fig. 4). This corresponds well with results from the clustering analysis that suggests that the presence of oil is the primary driver of responses across treatments. Functions with weaker responses overall tended to be more variable and did not exhibit clear reversals in responses when co-exposed with oil (i.e. "Cell death of ventricular myocytes", Fig. 4). This suggests that there are complex interactions driving the effects seen at the functional level and that co-exposure to oil and an abiotic stressor may exacerbate effects seen in exposures to an individual stressor. Interrogation into predicted diseases and bio functions resulted in widescale activation with oil, hypoxia, and the co-exposure of oil and hypoxia treatments eliciting the most cardiovascular effects (Fig. 5), again suggesting that the presence of oil modulates the responses seen across treatments. Processes involved in the development of the vasculature were activated in all treatments involving oil but reduced in the hypoxia only treatment. This response aligns well with the "Inhibition of angiogenesis by TSP1" seen in the canonical pathway analysis (Fig. 3). TSP1 (thrombospondin 1) is an angiogenesis inhibitor that works by inducing endothelial cell apoptosis and is induced under hypoxic conditions (Moulton and Folkman, 2004; Phelan et al., 1998). It is therefore unsurprising that exposure to hypoxia resulted in inhibition of development of vasculature and other vasculogenesis/angiogenesis processes (Fig. 5). Processes involved in blood pressure disorders were largely inhibited in all treatments involving oil, with a slight activation in the hypoxia only treatment. These results correlate well with effects seen in pathways involved in blood pressure maintenance. Specifically, the inhibition of blood pressure disorders in the combined oil and abiotic factor treatments (Fig. 5) align with the activation of signaling pathways involved in blood pressure maintenance (Aldosterone, Apelin, and Renin-Angiotensin, Fig. 3).
Along with evidence supporting changes in structural morphology of the developing cardiac system, these results provide a holistic view of the impacts of multiple stressors on the cardiovascular system. The data suggests that processes regulating blood pressure maintenance are increased in response to inhibited cardiovascular function which appears to be driven by increased cardiomyocyte proliferation and reduced development of the systemic vasculature.

This study is one of the first to concomitantly examine the effects of oil and environmental abiotic stressors through the lens of transcriptomic changes related to cardiac development and function. Trends apparent throughout the multiple levels of analysis in this study support previous findings regarding environmental influences on the cardiac transcriptomes of early life history fish when exposed to a single stressor (Carls et al., 2008; Claireaux et al., 1995; Farrell, 2007; Incardona et al., 2009, 2011, 2014; Jayasundara et al., 2015; Keen et al., 2017; Khursigara et al., 2017; Klaiman et al., 2011; Lin et al., 1994; Randall and Smith, 1967). Work presented here expands that knowledge to include trends apparent when fish are co-exposed to oil and abiotic stressors. Overall, responses appear to be structured through complex interactions and the transcriptomic responses to binary exposures do not appear to be the additive result of responses to two single exposures. The presence of oil in combination with abiotic stressors impacted signaling pathways and cardiovascular functions through changes in cardiomyocyte proliferation, cardiac hypertrophy, alterations in contractility, and modulation of blood pressure maintenance. Further, the development of systemic vasculature appears to be heavily impacted by combined exposures of oil and sub-optimal abiotic conditions. Predominant trends across all levels of predictive downstream analysis suggests that cardiac impairment due to co-exposure to oil and an abiotic stressor presents as cardiac hypertrophy driven by increased cardiac proliferation and results in reduced contractility and modulation of blood pressure.

Supplementary data to this article can be found online at https://doi. org/10.1016/j.scitotenv.2020.142156.

\section{CRediT authorship contribution statement}

Elizabeth Allmon: Data curation, Formal analysis, Validation, Visualization, Writing - original draft. Jennifer Serafin: Data curation, Formal analysis, Validation, Visualization. Shuai Chen: Data curation, Formal analysis, Validation, Visualization, Writing - review \& editing. Maria L. Rodgers: Formal analysis, Writing - review \& editing. Robert Griffitt: Conceptualization, Funding acquisition, Resources, Writing review \& editing. Thijs Bosker: Conceptualization, Funding acquisition, Resources, Writing - review \& editing. Sylvain de Guise: Conceptualization, Funding acquisition, Resources, Writing - review \& editing. Maria S. Sepúlveda: Conceptualization, Funding acquisition, Project administration, Resources, Supervision, Writing - review \& editing.

\section{Declaration of competing interest}

The authors declare that they have no known competing financial interests or personal relationships that could have appeared to influence the work reported in this paper.

\section{Acknowledgements}

This research was made possible by a grant from BP/The Gulf of Mexico Research Initiative II (award number SA 13-01/GoMRI-009) awarded to TB, MSS, RJG, SDG and CP. The funders had no role in the design, execution, or analyses of this project. The data are archived at Gulf of Mexico Research Initiative Information and Data Cooperative, doi: https://doi.org/10.7266/n7-sef2-8e60 (R6.x814.000:0004) and https:// doi.org/10.7266/VBQ60WSC (R6.x814.000:0008). Sam Guffey assisted with many aspects of the study. Christopher Perkins, Department of 
Pathobiology and Veterinary Science, University of Connecticut, performed the PAH analyses. We thank the Purdue College of Agriculture and the Department of Forestry and Natural Resources for supporting EA with a Research/Teaching Assistantship (Andrews Fellowship).

\section{References}

Andersen, Ø., Frantzen, M., Rosland, M., Timmerhaus, G., Skugor, A., Krasnov, A., 2015. Effects of crude oil exposure and elevated temperature on the liver transcriptome of polar cod (Boreogadus saida). Aquat. Toxicol. 165, 9-18. https://doi.org/10.1016/j. aquatox.2015.04.023.

Andrews, S., 2010. FastQC: A Quality Control Tool for High Throughput Sequence Data.

Bailey, J.R., Driedzic, W.R., 1986. Function of myoglobin in oxygen consumption by isolated perfused fish hearts. Am. J. Phys. Regul. Integr. Comp. Phys. 251, R1144-R1150. https://doi.org/10.1152/ajpregu.1986.251.6.r1144.

Bennett, W.A., Beitinger, T.L., 1997. Temperature tolerance of the sheepshead minnow. Copeia 77-87.

Beyer, J., Trannum, H.C., Bakke, T., Hodson, P.V., Collier, T.K., 2016. Environmental effects of the Deepwater Horizon oil spill: a review. Mar. Pollut. Bull. 110, 28-51. https:// doi.org/10.1016/j.marpolbul.2016.06.027.

Bodine, S.C., Baehr, L.M., 2014. Skeletal muscle atrophy and the E3 ubiquitin ligases MuRF1 and MAFbx/atrogin-1. Am. J. Physiol. Endocrinol. Metab. 307, E469-E484. https://doi.org/10.1152/ajpendo.00204.2014.

Bolger, A.M., Lohse, M., Usadel, B., 2014. Trimmomatic: a flexible trimmer for Illumina sequence data. Bioinformatics 30, 2114-2120. https://doi.org/10.1093/bioinformatics/ btu170.

Borowiec, B.G., Darcy, K.L., Gillette, D.M., Scott, G.R., 2015. Distinct physiological strategies are used to cope with constant hypoxia and intermittent hypoxia in killifish (Fundulus heteroclitus). J. Exp. Biol. 218, 1198-1211. https://doi.org/10.1242/ jeb.114579.

Camilli, R., Di Iorio, D., Bowen, A., Reddy, C.M., Techet, A.H., Yoerger, D.R., Whitcomb, L.L., Seewald, J.S., Sylva, S.P., Fenwick, J., 2012. Acoustic measurement of the Deepwater Horizon Macondo well flow rate. Proc. Natl. Acad. Sci. 109, 20235-20239. https:// doi.org/10.1073/pnas.1100385108.

Carls, M.G., Holland, L., Larsen, M., Collier, T.K., Scholz, N.L., Incardona, J.P., 2008. Fish embryos are damaged by dissolved PAHs, not oil particles. Aquat. Toxicol. 88, 121-127. https://doi.org/10.1016/j.aquatox.2008.03.014.

Carvalho, P.S.M., Kalil, D. da C.B., Novelli, G.A.A., Bainy, A.C.D., Fraga, A.P.M., 2008. Effects of naphthalene and phenanthrene on visual and prey capture endpoints during early stages of the dourado Salminus brasiliensis. Mar. Environ. Res. 66, 205-207. https:// doi.org/10.1016/j.marenvres.2008.02.059.

Claireaux, G., Webber, D.M., Kerr, S.R., Boutilier, R.G., 1995. Physiology and behaviour of free-swimming Atlantic cod (Gadus morhua) facing fluctuating temperature conditions. J. Exp. Biol. 198, 49-60.

Clark, B.W., Matson, C.W., Jung, D., Di Giulio, R.T., 2010. AHR2 mediates cardiac teratogenesis of polycyclic aromatic hydrocarbons and PCB-126 in Atlantic killifish (Fundulus heteroclitus). Aquat. Toxicol. 99, 232-240. https://doi.org/10.1016/j.aquatox.2010.05.004.

Cleveland, B.M., Evenhuis, J.P., 2010. Molecular characterization of atrogin-1/F-box protein-32 (FBX032) and F-box protein-25 (FBXO25) in rainbow trout (Oncorhynchus mykiss): expression across tissues in response to feed deprivation. Comp. Biochem. Physiol. B Biochem. Mol. Biol. 157, 248-257. https://doi. org/10.1016/j.cbpb.2010.06.010.

Collier, T.K., Anulacion, B.F., Arkoosh, M.R., Dietrich, J.P., Incardona, J.P., Johnson, L.L. Ylitalo, G.M., Myers, M.S., 2013. Effects on fish of polycyclic aromatic hydrocarbons (PAHs) and naphthenic acid exposures. Fish Physiology, First Edit. ed Elsevier Inc, pp. 195-255 https://doi.org/10.1016/B978-0-12-398254-4.00004-2.

De Theije, C.C., Langen, R.C.J., Lamers, W.H., Gosker, H.R., Schols, A.M.W.J., Köhler, S.E., 2015. Differential sensitivity of oxidative and glycolytic muscles to hypoxia-induced muscle atrophy. J. Appl. Physiol. 118, 200-211. https://doi org/10.1152/japplphysiol.00624.2014.

Edmunds, R.C., Gill, J.A., Baldwin, D.H., Linbo, T.L., French, B.L., Brown, T.L., Esbaugh, A.J., Mager, E.M., Stieglitz, J., Hoenig, R., Benetti, D., Grosell, M., Scholz, N.L., Incardona, J.P., 2015. Corresponding morphological and molecular indicators of crude oil toxicity to the developing hearts of mahi mahi. Sci. Rep. 5, 1-18. https://doi.org/10.1038/ srep17326.

Esbaugh, A.J., Mager, E.M., Stieglitz, J.D., Hoenig, R., Brown, T.L., French, B.L., Linbo, T.L., Lay, C., Forth, H., Scholz, N.L., Incardona, J.P., Morris, J.M., Benetti, D.D., Grosell, M., 2016. The effects of weathering and chemical dispersion on Deepwater Horizon crude oil toxicity to mahi-mahi (Coryphaena hippurus) early life stages. Sci. Total Environ. 543, 644-651. https://doi.org/10.1016/j.scitotenv.2015.11.068.

Farrell, A.P., 2007. Tribute to P. L. Lutz: a message from the heart - why hypoxic bradycardia in fishes? J. Exp. Biol. 210, 1715-1725. https://doi.org/10.1242/jeb.02781.

Forth, H.P., Mitchelmore, C.L., Morris, J.M., Lay, C.R., Lipton, J., 2017a. Characterization of dissolved and particulate phases of water accommodated fractions used to conduct aquatic toxicity testing in support of the Deepwater Horizon natural resource damage assessment. Environ. Toxicol. Chem. 36, 1460-1472. https://doi org/10.1002/etc.3803.

Forth, H.P., Mitchelmore, C.L., Morris, J.M., Lipton, J., 2017b. Characterization of oil and water accommodated fractions used to conduct aquatic toxicity testing in support of the Deepwater Horizon oil spill natural resource damage assessment. Environ. Toxicol. Chem. 36, 1450-1459. https://doi.org/10.1002/etc.3672.

Greely, M.S., MacGregor, R., 1983. Annual and semilunar reproductive cycles of the Gulf killifish, Fundulus grandis, on the Alabama Gulf coast. Copeia 711-718.

Green, C., 2013. Intensive (Non-pond) Culture of Gulf Killifish. SRAC Publ. No. 2012.
Greer, C.D., Hodson, P.V., Li, Z., King, T., Lee, K., 2012. Toxicity of crude oil chemically dispersed in a wave tank to embryos of Atlantic herring (Clupea harengus). Environ. Toxicol. Chem. 31, 1324-1333. https://doi.org/10.1002/etc.1828.

Haney, D.C., Nordlie, F.G., 1997. Influence of environmental salinity on routine metabolic rate and critical oxygen tension of Cyprinodon variegatus. Physiol. Zool. 70, 511-518. https://doi.org/10.1086/515867.

Hedgpeth, B.M., Griffitt, R.J., 2016. Simultaneous exposure to chronic hypoxia and dissolved polycyclic aromatic hydrocarbons results in reduced egg production and larval survival in the sheepshead minnow (Cyprinodon variegatus). Environ. Toxicol. Chem 35, 645-651. https://doi.org/10.1002/etc.3207.

Incardona, J.P., Carls, M.G., Day, H.L., Sloan, C.A., Bolton, J.L., Collier, T.K., Schoiz, N.L., 2009 Cardiac arrhythmia is the primary response of embryonic Pacific herring (Clupea pallasi) exposed to crude oil during weathering. Environ. Sci. Technol. 43, 201-207. https://doi.org/10.1021/es802270t.

Incardona, J.P., Collier, T.K., Scholz, N.L., 2011. Oil spills and fish health: exposing the heart of the matter. J. Expo. Sci. Environ. Epidemiol. 21, 3-4. https://doi.org/10.1038/ jes.2010.51.

Incardona, J.P., Gardner, L.D., Linbo, T.L., Brown, T.L., Esbaugh, A.J., Mager, E.M., Stieglitz J.D., French, B.L., Labenia, J.S., Laetz, C.A., Tagal, M., Sloan, C.A., Elizur, A., Benetti, D.D., Grosell, M., Block, B.A., Scholz, N.L., 2014. Deepwater Horizon crude oil impacts the developing hearts of large predatory pelagic fish. Proc. Natl. Acad. Sci. 111, E1510-E1518. https://doi.org/10.1073/pnas.1320950111.

Jasperse, L., Levin, M., Rogers, K., Perkins, C., Bosker, T., Griffitt, R.J., Sepúlveda, M., De Guise, S., 2019. Hypoxia and reduced salinity exacerbate the effects of oil exposure on sheepshead minnow (Cyprinodon variegatus) reproduction. Aquat. Toxicol. 212, 175-185. https://doi.org/10.1016/j.aquatox.2019.05.002.

Jayasundara, N., Van Tiem Garner, L., Meyer, J.N., Erwin, K.N., Di Giulio, R.T., 2015. AHR2 mediated transcriptomic responses underlying the synergistic cardiac developmenta toxicity of PAHs. Toxicol. Sci. 143, 469-481. https://doi.org/10.1093/toxsci/kfu245.

Jones, E.R., Simning, D., Serafin, J., Sepúlveda, M.S., Griffitt, R.J., 2020. Acute exposure to oi induces age and species-specific transcriptional responses in embryo-larval estuarine fish. Environ. Pollut. 263, 1-10. https://doi.org/10.1016/j.envpol.2020.114325.

Keen, A.N., Klaiman, J.M., Shiels, H.A., Gillis, T.E., 2017. Temperature-induced cardiac remodelling in fish. J. Exp. Biol. 220, 147-160. https://doi.org/10.1242/jeb.128496.

Khursigara, A.J., Perrichon, P., Martinez Bautista, N., Burggren, W.W., Esbaugh, A.J., 2017. Cardiac function and survival are affected by crude oil in larval red drum, Sciaenops ocellatus. Sci. Total Environ. 579, 797-804. https://doi.org/10.1016/j.scitotenv.2016.11.026.

Kim, K., Jeon, H.J., Choi, S.D., Tsang, D.C.W., Oleszczuk, P., Ok, Y.S., Lee, H.S., Lee, S.E., 2018. Combined toxicity of endosulfan and phenanthrene mixtures and induced molecular changes in adult zebrafish (Danio rerio). Chemosphere 194, 30-41. https://doi.org/ 10.1016/j.chemosphere.2017.11.128.

Klaiman, J.M., Fenna, A.J., Shiels, H.A., Macri, J., Gillis, T.E., 2011. Cardiac remodeling in fish: strategies to maintain heart function during temperature change. PLoS One 6, 1-11. https://doi.org/10.1371/journal.pone.0024464.

Kolde, R., 2012. Pheatmap: Pretty Heatmaps.

Lin, H., Pfeiffer, D., Vogl, A., Pan, J., Randall, D., 1994. Immunolocalization of H+-ATPase in the gill epithelia of rainbow trout. J. Exp. Biol. 195, 169-183.

Mager, E.M., Esbaugh, A.J., Stieglitz, J.D., Hoenig, R., Bodinier, C., Incardona, J.P., Scholz, N.L. Benetti, D.D., Grosell, M., 2014. Acute embryonic or juvenile exposure to Deepwater Horizon crude oil impairs the swimming performance of mahi-mahi (Coryphaena hippurus). Environ. Sci. Technol. 48, 7053-7061. https://doi.org/10.1021/es501628k.

Magnuson, J.T., Khursigara, AJ, Allmon, E.B., Esbaugh, A.J., Roberts, A.P., 2018. Effects of Deepwater Horizon crude oil on ocular development in two estuarine fish species, red drum (Sciaenops ocellatus) and sheepshead minnow (Cyprinodon variegatus). Ecotoxicol. Environ. Saf. 166, 186-191. https://doi.org/10.1016/j.ecoenv.2018.09.087.

Mauduit, F., Farrell, A.P., Domenici, P., Lacroix, C., Le Floch, S., Lemaire, P., Nicolas-Kopec, A., Whittington, M., Le Bayon, N., Zambonino-Infante, J.-L., Claireaux, G., 2018. Assessing the long-term effect of exposure to dispersant-treated oil on fish health using hypoxia tolerance and temperature susceptibility as ecologically relevant biomarkers. Environ. Toxicol. Chem. 38, 210-221. https://doi.org/10.1002/etc.4271.

McNutt, M.K., Camilli, R., Crone, T.J., Guthrie, G.D., Hsieh, P.A., Ryerson, T.B., Savas, O. Shaffer, F., 2012. Review of flow rate estimates of the Deepwater Horizon oil spill. Proc. Natl. Acad. Sci. 109, 20260-20267. https://doi.org/10.1073/pnas.1112139108.

Milinkovitch, T., Marras, S., Antognarelli, F., Lefrançois, C., Le Floch, S., Domenici, P., 2020. The effects of hypoxia on aerobic metabolism in oil-contaminated sea bass (Dicentrarchus labrax). Chemosphere. 253, 1-7. https://doi.org/10.1016/j. chemosphere.2020.126678.

Mimura, J., Ema, M., Sogawa, K., Fujii-Kuriyama, Y., 1999. Identification of a novel mechanism of regulation of Ah (dioxin) receptor function. Genes Dev. 13, 20-25. https:// doi.org/10.1101/gad.13.1.20.

Moulton, K.S., Folkman, J., 2004. Angiogenesis in cardiovascular disease. Molecular Basis of Cardiovascular Disease: A Companion to Braunwald's Heart Disease. Elsevier Inc, pp. 433-454 https://doi.org/10.1016/B978-0-7216-9428-3.50029-9.

Muhling, B.A., Roffer, M.A., Lamkin, J.T., Ingram, G.W., Upton, M.A., Gawlikowski, G., Muller-Karger, F., Habtes, S., Richards, W.J., 2012. Overlap between Atlantic bluefin tuna spawning grounds and observed Deepwater Horizon surface oil in the northern Gulf of Mexico. Mar. Pollut. Bull. 64, 679-687. https://doi.org/ 10.1016/j.marpolbul.2012.01.034.

Murphy, D., Gemmell, B., Vaccari, L., Li, C., Bacosa, H., Evans, M., Gemmell, C., Harvey, T. Jalali, M., Niepa, T.H.R., 2016. An in-depth survey of the oil spill literature since 1968: long term trends and changes since Deepwater Horizon. Mar. Pollut. Bull. 113, 371-379. https://doi.org/10.1016/j.marpolbul.2016.10.028.

Norse, E.A., Amos, J., 2010. Impacts, perception, and policy implications of the Deepwater Horizon oil and gas disaster. Environ. Law Report. 40, 11058-11073. https://doi.org/ 10.1038/nn.2937. 
Oleksiak, M.F., Karchner, S.I., Jenny, M.J., Franks, D.G., Mark Welch, D.B., Hahn, M.E., 2011. Transcriptomic assessment of resistance to effects of an aryl hydrocarbon receptor (AHR) agonist in embryos of Atlantic killifish (Fundulus heteroclitus) from a marine superfund site. BMC Genomics 12, 1-18. https://doi.org/10.1186/1471-2164-12-263.

Orlando, S.P.J., Rozas, L.P., Ward, G.H., Klein, C.J., 1993. Salinity characteristics of Gulf of Mexico estuaries. Natl. Ocean. Atmos. Adm. Off. Ocean Resour. Conserv. Assess. https://doi.org/10.1016/0004-6981(75)90067-0.

Pan, Y.K., Khursigara, A.J., Johansen, J.L., Esbaugh, A.J., 2018. The effects of oil induced respiratory impairment on two indices of hypoxia tolerance in Atlantic croaker (Micropogonias undulatus). Chemosphere 200, 143-150. https://doi.org/10.1016/j. chemosphere.2018.02.028.

Phelan, M.W., Forman, L.W., Perrine, S.R., Faller, D.V., 1998. Hypoxia increases thrombospondin-1 transcript and protein in cultured endothelial cells. J. Lab. Clin. Med. 132, 519-529. https://doi.org/10.1016/S0022-2143(98)90131-7.

Powell, W.H., Morrison, H.G., Weil, E.J., Karchner, S.I., Sogin, M.L., Stegeman, J.J., Hahn, M.E., 2004. Cloning and analysis of the CYP1A promoter from the Atlantic killifish (Fundulus heteroclitus). Mar. Environ. Res. 58, 119-124. https://doi.org/10.1016/j. marenvres.2004.03.005.

Rabalais, N.N., Turner, R.E., Wiseman, W.J., 2002. Gulf of Mexico hypoxia, a.k.a. "the dead zone". Annu. Rev. Ecol. Syst. 33, 235-263. https://doi.org/10.1146/ annurev.ecolsys.33.010802.150513.

Randall, D.J., Smith, J.C., 1967. The regulation of cardiac activity in fish in a hypoxic environment. Physiol. Zool. 40, 104-113. https://doi.org/10.1086/physzool.40.2.30152445.

Reid, N.M., Proestou, D.A., Clark, B.W., Warren, W.C., Colbourne, J.K., Shaw, J.R., Karchner, S.I., Hahn, M.E., Nacci, D., Oleksiak, M.F., Crawford, D.L., Whitehead, A., 2016. The genomic landscape of rapid repeated evolutionary adaptation to toxic pollution in wild fish. Science 354, 1305-1308. https://doi.org/10.1126/science.aah4993.

Rodgers, M.L., Jones, E.R., Klinkhamer, C., Mahapatra, C.T., Serafin, J., Bosker, T., Perkins, C. Griffitt, R.J., De Guise, S., Sepúlveda, M.S., 2018. Combined effects of Deepwater Horizon crude oil and environmental stressors on Fundulus grandis embryos. Environ. Toxicol. Chem. 37, 1916-1925. https://doi.org/10.1002/etc.4153.

Rooker, J.R., Kitchens, L.L., Dance, M.A., Wells, R.J.D., Falterman, B., Cornic, M., 2013. Spatial, temporal, and habitat-related variation in abundance of pelagic fishes in the Gulf of Mexico: potential implications of the Deepwater Horizon oil spill. PLoS One 8, 1-10. https://doi.org/10.1371/journal.pone.0076080.

Sammarco, P.W Kolian, S.R Warby, R.AF, Bouldin, J.L Subra, W. A Porter, S.A. 2013. Distribution and concentrations of petroleum hydrocarbons associated with the BP/ Deepwater Horizon oil spill, Gulf of Mexico. Mar. Pollut. Bull. 73, 129-143. https:// doi.org/10.1016/j.marpolbul.2013.05.029.

Schlenk, D., Celander, M., Gallagher, E.P., George, S., James, M., Kullman, S.W., Van Den Hurk, P., Willett, K., 2008. Biotransformation in fishes. The Toxicology of Fishes. CRC Press, pp. 153-234 https://doi.org/10.1201/9780203647295.

Schroeder, W.W., Wiseman, W.J., 1986. Low-frequency shelf-estuarine exchange processes in Mobile Bay and other estuarine systems on the Northern Gulf of Mexico.
Estuarine Variability. Academic Press, Inc, pp. 355-367 https://doi.org/10.1016/ B978-0-12-761890-6.50027-7.

Serafin, J., 2017. Combined Effects of Environmental Stressors and Crude Oil in Fundulus grandis Development and Transcriptome. Purdue University.

Serafin, J., Guffey, S.C., Bosker, T., Griffitt, R.J., De Guise, S., Perkins, C., Szuter, M., Sepúlveda, M.S., 2019. Combined effects of salinity, temperature, hypoxia, and Deepwater Horizon oil on Fundulus grandis larvae. Ecotoxicol. Environ. Saf. 181, 106-113. https://doi.org/10.1016/j.ecoenv.2019.05.059.

Shimada, T., Fujii-Kuriyama, Y., 2004. Metabolic activation of polycyclic aromatic hydrocarbons to carcinogens by cytochromes P450 1A1 and 1B1. Gann Monogr. Cancer Res. 52, 109-124. https://doi.org/10.1111/j.1349-7006.2004.tb03162.x.

Simning, D., Sepulveda, M., De Guise, S., Bosker, T., Griffitt, R.J., 2019. The combined effects of salinity, hypoxia, and oil exposure on survival and gene expression in developing sheepshead minnows, Cyprinodon variegatus. Aquat. Toxicol. 214, 1-19. https://doi. org/10.1016/j.aquatox.2019.105234.

Untergasser, A., Nijveen, H., Rao, X., Bisseling, T., Geurts, R., Leunissen, J.A.M., 2007. Primer3Plus, an enhanced web interface to Primer3. Nucleic Acids Res. 35, W71-W74. https://doi.org/10.1093/nar/gkm306.

Vandesompele, J., De Preter, K., Pattyn, F., Poppe, B., Van Roy, N., De Paepe, A., Speleman, F., Åman, P., Semb, H., Powers, D., Aurias, A., Thomas, G., 2002. The multifunctional FUS, EWS and TAF15 proto-oncoproteins show cell type-specific expression patterns and involvement in cell spreading and stress response. Genome Biol. 3, 1-12. https:// doi.org/10.1186/gb-2002-3-7-research0034.

Whitehead, A., Roach, J.L., Zhang, S., Galvez, F., 2011. Genomic mechanisms of evolved physiological plasticity in killifish distributed along an environmental salinity gradient. Proc. Natl. Acad. Sci. U. S. A. 108, 6193-6198. https://doi.org/10.1073/pnas.1017542108.

Xu, E.G., Mager, E.M., Grosell, M., Pasparakis, C., Schlenker, L.S., Stieglitz, J.D., Benetti, D., Hazard, E.S., Courtney, S.M., Diamante, G., Freitas, J., Hardiman, G., Schlenk, D., 2016. Time- and oil-dependent transcriptomic and physiological responses to Deepwater Horizon oil in mahi-mahi (Coryphaena hippurus) embryos and larvae. Environ. Sci. Technol. 50, 7842-7851. https://doi.org/10.1021/acs.est.6b02205.

Xu, E.G., Khursigara, A.J., Magnuson, J., Hazard, E.S., Hardiman, G., Esbaugh, A.J., Roberts, A.P., Schlenk, D., 2017a. Larval red drum (Sciaenops ocellatus) sublethal exposure to weathered Deepwater Horizon crude oil: developmental and transcriptomic consequences. Environ. Sci. Technol. 51, 10162-10172. https://doi.org/10.1021/acs. est.7b02037.

Xu, E.G., Mager, E.M., Grosell, M., Hazard, E.S., Hardiman, G., Schlenk, D., 2017b. Novel transcriptome assembly and comparative toxicity pathway analysis in mahi-mahi (Coryphaena hippurus) embryos and larvae exposed to Deepwater Horizon oil. Sci. Rep. 7, 1-13. https://doi.org/10.1038/srep44546.

Zhu, C.D., Wang, Z.H., Yan, B., 2013. Strategies for hypoxia adaptation in fish species: a review. J. Comp. Physiol. B Biochem. Syst. Environ. Physiol. 183, 1005-1013. https://doi. org/10.1007/s00360-013-0762-3.

Zinkle, A., Mohammadi, M., 2019. Structural biology of the FGF7 subfamily. Front. Genet. 10, 1-8. https://doi.org/10.3389/fgene.2019.00102. 